\title{
Analysis of Cotton Yarn Properties Spun on Aerodynamic Compact and Open-End Rotor Spinning
}

\author{
Md. Rafiqul Islam, Suza Ahmed* ${ }^{*}$, Md. Abubakar Siddik, Sadik M. Ashique \\ Department of Textile Engineering, National Institute of Textile Engineering and Research (NITER), Nayarhat, Savar, \\ Dhaka, Bangladesh \\ Email: *suzaahmed03@gmail.com
}

How to cite this paper: Islam, Md.R., Ahmed, S., Siddik, Md.A. and Ashique, S.M. (2021) Analysis of Cotton Yarn Properties Spun on Aerodynamic Compact and Open-End Rotor Spinning. Journal of Textile Science and Technology, 7, 22-40. https://doi.org/10.4236/jtst.2021.71003

Received: November 17, 2020

Accepted: February 7, 2021

Published: February 10, 2021

Copyright $\odot 2021$ by author(s) and Scientific Research Publishing Inc. This work is licensed under the Creative Commons Attribution International License (CC BY 4.0).

http://creativecommons.org/licenses/by/4.0/

\begin{abstract}
This article presents a comparative analysis of the properties of cotton yarn spun on aerodynamic compact spinning and open-end rotor spinning systems. Yarn samples with a linear density of 50 Tex, 37 Tex, 30 Tex, 25 Tex, and 20 Tex were spun both on the aerodynamic compact and rotor spinning systems using the same finisher drawn sliver of medium staple cotton which were produced by a specific mixing. The quality parameters such as mass variation, imperfection index, hairiness, and tensile behavior (strength in count strength product, elongation percentage) of the yarn samples were assessed and analyzed. The results revealed that aerodynamic compact spun yarn had a lower unevenness and mass variation, a higher imperfection in case of a finer count, less hairiness, higher tensile strength, and lower elongation $\%$ compared to the open-end rotor spun yarn samples. Finally, pairedsamples t-test and regression analysis were carried out by using IBM SPSS 25 to check the significance of yarn quality parameters and correlation among them.
\end{abstract}

\section{Keywords}

Compact Yarn, Rotor Yarn, Imperfection, Hairiness, Tensile Strength

\section{Introduction}

The global competitive situation has forced the modern textile market to focus vigorously on issues like productivity and cost reduction in manufacturing yarn and fabric while maintaining the quality at a high level. Yarn is the prime raw material in fabric manufacturing, like weaving, knitting, and narrow weaving. For maximizing yarn productivity, an increase in the production rate of the 
spinning machine is necessary. During spinning, the yarn is spun in a simplex machine and ring frame sequentially. The produced material from simplex is fed into the ring frame. Generally, the production rate in the ring frame determines the production output [1] [2]. Textile industries have come out from the concept of conventional ring spinning to enhance productivity and modify the yarn with different structures and properties. Ring-spun yarn, however, has always been the acknowledged quality benchmark within the spun yarn sector [3]. The ring and rotor are two basic spinning systems. In the case of ring spinning, the twist is inserted into yarn by the aid of a rotating traveler. Twisting and wind-up take place simultaneously. The structure of ring yarn is generally assumed as the basic structure in spun yarn technology. Nevertheless, in compact spinning, tension differences between fibers during the twist insertion are smaller than those in-ring spinning due to the reduction of the spinning triangle [4]. It has been claimed that compact spinning has the possibility of attaining yarn strength identical to that in typical ring yarn with approximately $10 \%$ lower twist [5]. Many open-end (OE) spinning has been invented, but none can replace the rotor spinning. In rotor spinning, the sliver (fibers bundle) is separated into individual fibers with an opening roller in an air stream, and separated fibers are re-collected in the rotor. The production rate of open-end rotor spinning (OERS) is up to 200 meters per minute for up to 20 Tex linear density [6].

This work endeavors to analyze and compare the parameters of cotton yarn spun on the Suessen EliTe ${ }^{\circledR}$ compact spinning frame and the open-end rotor spinning frame. Yarns spun on compact spinning have better advantages when compared to open-end rotor spinning in terms of tensile strength and elongation\%, mass irregularity on short segments, hairiness, and imperfection index. The analysis allows us to assume the quality parameters of spun yarns for any given linear mass and enables the modeling of yarn parameters for different carded yarn, spun with the use of the compact and rotor to avoid probable faults during spinning.

\section{Literature Review}

Textile yarns can be classified according to spinning systems like the ring, compact, rotor, air-jet, friction, and spun yarn. Ring spinning is a universal system, although it has some limitations like small yarn package size, limited spindle speed, traveler speed, ballooning, and the spinning triangle resulting in higher cost and less productivity [7]. So, bound to try a new spinning system, aerodynamic compact and open-end rotor spinning are two of the most established methods. These spinning systems undoubtedly have a distinctive production edge over the ring spinning system. Alternatively, researchers have also focused on enhancing the production of ring yarn by overcoming those limitations [3] [8] [9].

\section{1) Aerodynamic compact spinning}

Ring yarn has a high amount of fibers, which not only fail to contribute to yarn strength but also increase yarn unevenness. Compact spinning is a novel 
approach through the re-engineering of a typical ring spinning process by attaching a pneumatic zone [10]. It eliminates the spinning triangle by condensing the fibers pneumatically or mechanically [11]. It can be achieved by condensing the fiber sheet in the drafting zone. The condensation can be achieved by the three ways [10]:

a) Roving twist: The twist in roving has a 2 -fold objective. Firstly, it prevents the roving from being disturbed before it enters the ring frame drafting. Secondly, the twist contains the spreading of the fiber sheet during the drafting process.

b) Mechanical condensing: Condensation of the fiber flow can be enhanced by a funnel-shaped condenser, located between the aprons and delivery rollers. However, it deteriorates the actual drafting by exerting unavoidable frictional forces on the fiber flow.

c) Aerodynamic condenser: An aerodynamic condensation happens by gentle aerodynamic forces after the drafting but before the yarn formation. The fiber flow reaching the spinning triangle is so narrow that all fibers can be caught uniformly. The small-sized spinning triangle allows for excellent yarn formation [12]. In the Suessen EliTe ${ }^{\circledR}$ compacting machine [13], an aerodynamic condensing zone is used, as shown in Figure 1.

An additional drafting zone [14] [15] is introduced in the $3 / 3$ double apron standard drafting system. A perforated lattice apron closely embraces a tubular profile. The delivery top

roller, fitted with rubber cots, presses the lattice apron against the hollow profile and drives the apron, forming the nipping delivery line. The tubular profile has a small slot towards the fiber flow direction, which commences at the immediate vicinity of the front roller, nipping line, and ends in the region of the delivery nipping line 1(b). An air current is created through the lattice apron via the slot towards the inside of the profile tube, which seizes the fibers immediately after they leave the front roller nipping line and condenses the fiber strand, which is conveyed by lattice apron and transported to the delivery path. As the slot is under negative pressure, it reaches right up to the nipping delivery line,

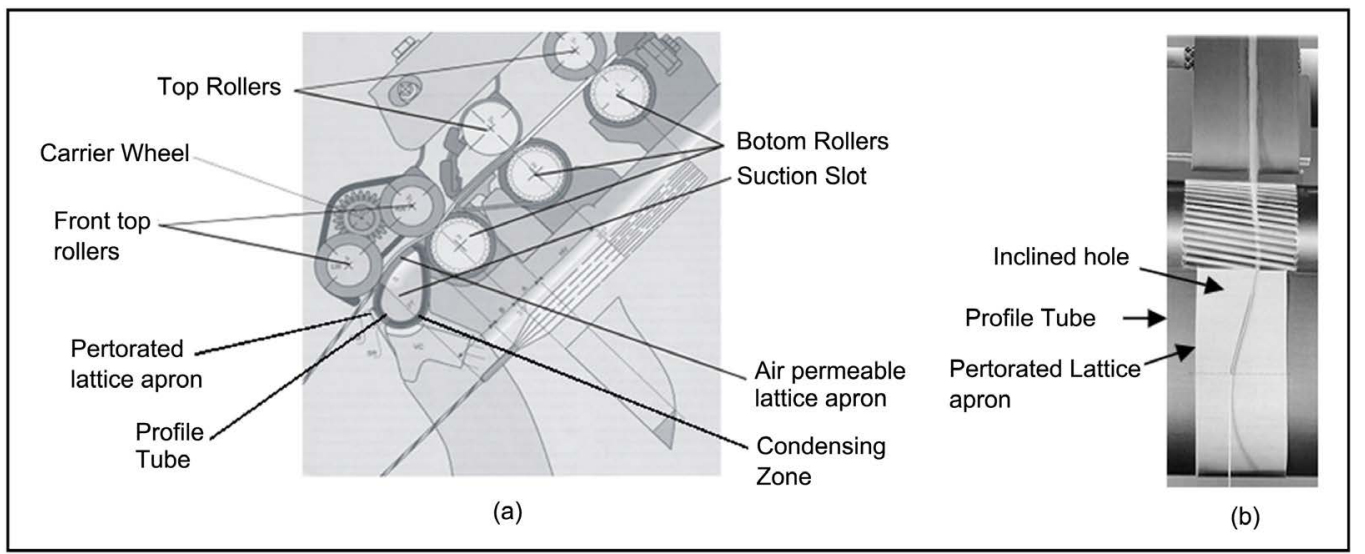

Figure 1. Compact spinning (a) Drafting zone; (b) Incline slot in tubular profile [1] [9] [13] [14]. 
and the fiber assembly remains compacted [1] [12] [13] [16]. Over 330,000 spindles of ring spinning with the EliTe compact drawing apparatus from Suessen are currently operating in spinning mills all over the world [17]. However, the first compact spinning frame for industrial use was built in 1995 [18].

\section{2) Open-end rotor spinning}

In rotor spinning, a conical sliver is continuously formed in a rotor groove, from staple fibers opened in the opening roller, and oriented employing centrifugal forces. At the thickest point of the conical sliver, fibers are twisted into the open yarn end rotating in the rotor, with the twists spreading to the delivery rollers. The fibers located in the yarn core cannot evade the imparting of twists, which results in higher yarn twist and the corresponding higher packing density in the yarn core. In the outer yarn structure, fibers can evade the twist impartation, making the yarn more voluminous. The wrapping fibers are wound around the yarn core in the form of a band. Underneath this is a thin fiber layer with few or partially opposing twists. If the fibers being applied to well-twisted yarn feature fewer permanent than false twists, the fibers are twisted in the opposite direction of the yarn twisting direction [19].

Both compact and rotor spinning were introduced to enhance spindle speed. It was observed that for compact spinning, with increased spindle speed, end breakage rate as well as yarn imperfection increases, and the yarn breaking extension decreases [2]. However, the spindle speed does not affect the yarn hairiness index compared to other factors [2]. Nevertheless, in the case of rotor spinning, maximum spindle speed depends on the rotor diameter and yarn strength. P. Grosberg and S. Mansour experimented on the rotor frame to enhance its speed up to 100,000 revolutions per minute (rpm) [20]. The spindle was modified slightly by reducing the rotating weight and overhanging length. Technologically, the main effect of increasing rotor speed is to increase the spinning tension, which will ultimately cause end breakage. However, there is a limitation for rotor spinning on the range of twists and linear densities that can be spun at different spinning speeds [20].

Mechanical properties of spun yarns depend on not only the physical properties of the fibers but also the yarn structure characterized by the arrangement of the individual fibers in yarn cross-section. Therefore, properties (yarn strength, extensibility, appearance, compactness, packing density) of a compact yarn and open-end rotor yarn are related to fiber distribution along yarn cross-section [21]. Fiber arrangements in open-end rotor yarns (Figure 2) are complicated because of their non-uniform appearance in comparison with ring-spun yarn, which has a uniform fiber core [4].

The number of belly-band fibers is highest in rotor yarn. Belly-band fibers are created when a fiber under high air pressure at the rotor surface is not able to blend with the common twisted strand and winds itself onto the yarn axis as it exits through the navel [4]. Rotor spun yarns have a densely packed core of fibers aligned with the central axis, loosely packed fibers twisted around the core at a considerable angle, and wrapper fibers on the outside. This type of structure 


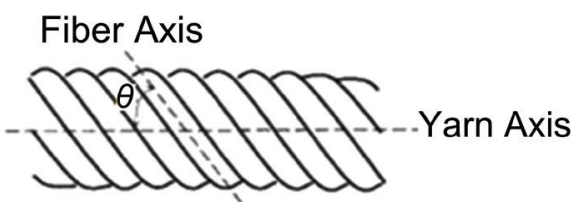

(a)

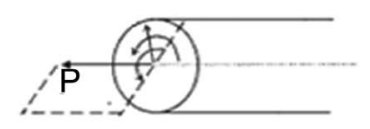

(b)

Figure 2. Stress analysis for fibers in a yarn [43] [44]. (a) ldealized Single Yarn Geometry; (b) General Stresses in Fiber.

makes rotor spun yarns successful in the commercial manufacture of coarser yarns. A scanning electron microscopic view shows (Figure 3) that a more compact yarn structure would be obtained as the yarns get finer [21]. The compact structure also shows less protruding fibers on the outer surface of the yarn, which will lead to less hairiness, increased uniformity and yarn strength [8] [9] [22]-[26].

Earlier it was found that packing densities of compact yarn is not always uniform in yarn cross-section, although compact yarns had approximately 30\% higher packing density compared to that of ring and rotor spun yarns [21]. Considering the idealized helical yarn geometry and it was ascertained that the higher the twist level, the larger the helix angle $\theta$, resulting in a more prominent compressive load [27]. Higher the compressive load, the more compact the yarn structure is. Again, the justified, thicker yarns have more fibers in their cross-sections, which results in a rise in total load (P), and hence the total compressive load acting on the yarn leads to increased packing density [27]. At the same yarn linear density, the rotor yarn is found bulkier than the ring-spun yarn [4].

Structural characteristics of Lyocell rotor yarn were observed by the tracer fiber method [28], which showed that a certain amount of fibers was transferred from the internal to external layer during rotor spinning. Moreover, there were more fiber reversal fragments inside of rotor yarn. The single yarn wet snarling counts were decreased due to those structural properties [28]. Nevertheless, while noticing the configurations of tracer fibers of the ring-spun yarn, it was assumed that ring yarn has an ideal cylindrical average helix angle of $17.2^{\circ}$ [29].

The main advantages of compact yarns are lower yarn hairiness, higher strength, and elongation values depending on their compactness [21]. The fibers in compact yarns are almost entirely integrated into the yarn body [3] [21] [30] [31]. The spinning speed does not affect the compact yarn strength variability [20]. The compact yarn has reduced the breakage rate of warping and weaving machines. The size consumption of the sizing machine is reduced by up to $50 \%$. It also provides good bursting strength in knitted fabrics [6]. The low hairiness index eliminates the singeing process, and dye consumption is also reduced. Fabric woven from compact yarn has improved tensile strength, pilling and abrasion resistance [18] [23] [32]. Open-end rotor spinning has several advantages 


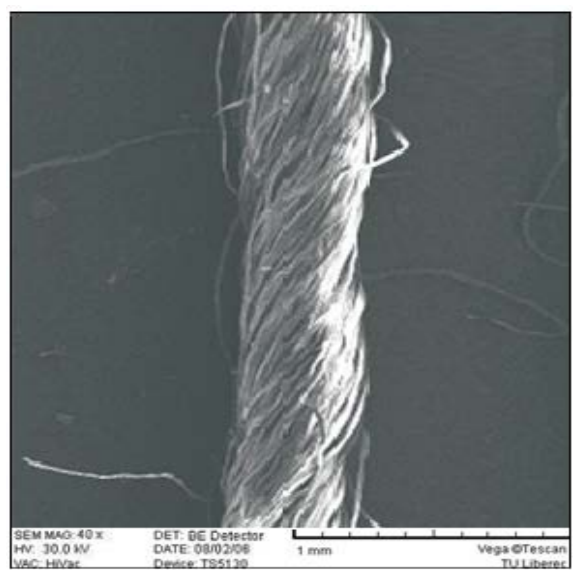

(a)

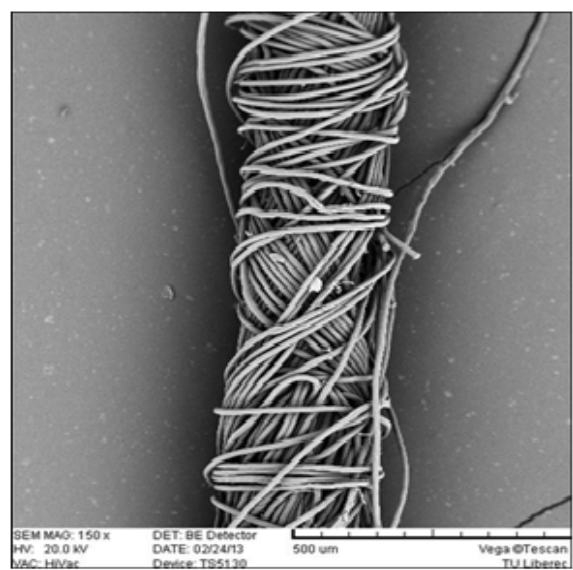

(b)

Figure 3. Surface of 20 Tex (a) Compact yarn [41] and (b) Open-end rotor yarn [42].

like increased production rate, separation of twisting and winding, and elimination of speed frame and winding. The effect of fiber fineness on the hairiness of yarns made using different spinning techniques is significant. Rotor spun yarn shows the highest deviation from ideal unevenness [33]. Rotor Spun yarns found with frequent breakage during knitting [6] and more irregular than ring yarn [34]. 100\% desirability satisfaction can be achieved for specific yarn quality parameters by process optimization, following USTER ${ }^{\circledR}$ benchmarks, at a rotor speed of 77,800 rpm and 700 twists per meter [35]. Rotor yarn of coarser count is used for denim fabric and tends to show a starting mark due to the creep behavior of yarn [36]. Rotor yarn has a lower maximum tensile load than a ring-spun yarn [19]. Advancements through the compact spinning and how it lacks from the rotor spinning, is the main purpose behind this work.

\section{Materials and Methodology}

\subsection{Materials}

Fifteen yarn sample sets (S1 to S15) of five different linear densities (3 samples of each linear density) of 50 Tex (S1 - S3), 37 Tex (S4 - S6), 30 Tex (S7 - S9), 25 Tex (S10 - S12), and 20 Tex (S13 - S15) was prepared by using $100 \%$ cotton fiber. Fibers from different origin (9\% Brazil $+41 \%$ Chad $+10 \%$ DCH32+ 40\% Cameroon) were mixed. The parameters of mentioned cotton fibers were tested on the USTER $^{\circledR}$ HVI (High-Volume Instrument) testing system and listed below in Table 1.

\subsection{Methodology}

\subsubsection{Yarn Preparation}

Each sample set contains one compact and one rotor yarn of the same linear density. All (S1 to S15) samples were spun both in compact and open-end rotor frames from the same finisher drawn sliver of 4494 Tex, which was prepared earlier by a typical spinning process. The finisher drawn sliver was converted to 
Table 1. Properties of cotton fiber.

\begin{tabular}{cc}
\hline Parameters & Mean value \\
\hline Uniformity Index $\left(U_{n f}\right)$ & $86 \%$ \\
Average length of the mixing & $30.75 \mathrm{~mm}$ \\
Short fiber Index (SFI) & $6.02 \%$ \\
Fineness & $160 \mathrm{~m} \mathrm{Tex}$ \\
Maturity Index (Mat) & 0.93 \\
Strength (Str) & $31.36 \mathrm{cN} / \mathrm{tex}$ \\
Elongation (Elg) & $7.5 \%$ \\
Moisture (Moist) & $8.9 \%$ \\
Reflectance (Rd) & 78.2 \\
Yellowness (+b) & 8.2 \\
Spinning Consistency Index (SCI) & 155 \\
\hline
\end{tabular}

725 Tex roving by a simplex machine before compacting. A Jingwei (F1520) ring spinning machine was used for this roving making. Later this roving was used to prepare compact yarn samples by the Suessen EliTe compacting system. Rotor yarn samples were prepared by Schlafhorst (ACO-8) rotor spinning machine from the mentioned finisher drawn sliver. All machines are materials that were provided by Multazim Spinning Mills Ltd., Mymensingh, Bangladesh. The process flow is given in Figure 4. Process parameters for compacting and rotor spinning is given below in Table 2 and Table 3.

\subsubsection{Determination of Irregularity Index}

The structural formation of every yarn confers different properties and parameters like irregularity, hairiness, strength, and bending [4]. Yarn irregularity index (I) is a measure of the unevenness deviation of a particular fiber that will be spun in an ideal situation, where $I$ will be 1 [33]. It can be determined by the following mathematical equation [33],

$$
n_{f}=\frac{T_{y}}{T_{f}}
$$

where $n_{f}$ is the number of fibers in the cross-section, $T_{y}$ is yarn fineness, and $T_{f}$ is fiber fineness. The limiting irregularity $C V_{\lim }$ was calculated by using the following equation [33] [37]:

$$
\begin{gathered}
C V_{\lim }=\frac{100}{\sqrt{n_{f}}} \\
\text { Irregularity index, } I=\frac{C V_{m}}{C V_{\lim }}
\end{gathered}
$$

where $C V_{m}$ is the coefficient of variation of unevenness and $C V_{\lim }$ is the limiting irregulity. The index also shows how well the machines run in certain technological phases and whether any deviations occur. 


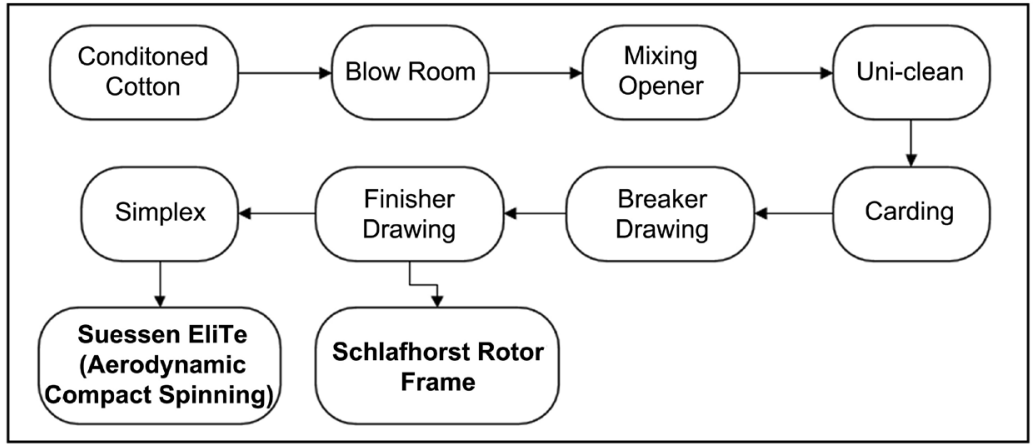

Figure 4. Flow chart of the spinning process.

Table 2. Process parameters of compact systems.

\begin{tabular}{|c|c|c|c|c|c|}
\hline Parameters & \multicolumn{5}{|c|}{ Suessen EliTe Compact spinning } \\
\hline Roving linear density, tex & \multicolumn{5}{|c|}{725 Tex } \\
\hline Drafting gauge, $\mathrm{mm}$ & \multicolumn{5}{|c|}{$44 \mathrm{~mm}$ (Front Zone) \& $54 \mathrm{~mm}$ (Back Zone) } \\
\hline Back draft & \multicolumn{5}{|c|}{1.29} \\
\hline Cradle load & \multicolumn{5}{|c|}{$12 \mathrm{Kgs}$} \\
\hline Lattice Apron type & \multicolumn{5}{|c|}{$\operatorname{Accotex}(36.5 \times 25.0 \mathrm{~mm})$} \\
\hline Lattice Apron density, holes $/ \mathrm{cm}^{2}$ & \multicolumn{5}{|c|}{3000} \\
\hline Ring diameter, $\mathrm{mm}$ & \multicolumn{5}{|c|}{$38 \mathrm{~mm}$} \\
\hline Twist Multiplier & \multicolumn{5}{|c|}{4.3} \\
\hline Yarn linear density, tex & 50 tex & 37 tex & 30 tex & 25 tex & 20 tex \\
\hline Sample no. & S1 - S3 & S4 - S6 & S7 - S9 & $\mathrm{S} 10-12$ & S13 - S15 \\
\hline Spindle speed, rpm & 12,000 & 12,000 & 14,000 & 15,000 & 16,000 \\
\hline Yarn twist per meter & 586 & 677 & 757 & 830 & 926 \\
\hline Spacer & $4.0 \mathrm{~mm}$ & $3.0 \mathrm{~mm}$ & $3.0 \mathrm{~mm}$ & $2.5 \mathrm{~mm}$ & $2.5 \mathrm{~mm}$ \\
\hline
\end{tabular}

Table 3. Process parameters of open-end rotor systems.

\begin{tabular}{cccccc}
\hline Parameters & \multicolumn{5}{c}{ Rotor Spinning } \\
\hline Yarn linear density, tex & 50 tex & 37 tex & 30 tex & 25 tex & 20 tex \\
Sample no. & S1 - S3 & S4 - S6 & S7 - S9 & S10 - 12 & S13 - S15 \\
Rotor speed, rpm & 75,000 & 75,000 & 80,000 & 90,000 & 90,000 \\
Yarn twist per meter & 640 & 740 & 827 & 907 & 1014 \\
Twist Multiplier & & 4.7 & & \\
Rotor diameter, mm & & & $40 \mathrm{~mm}$
\end{tabular}

\subsubsection{Testing Methods}

Mass variation, imperfection, and hairiness were determined by USTER ${ }^{\circledR}$ Tester 5 following ASTM D1425-96 standard test method. Mass variation can be expressed in terms of unevenness $(L \%)$ and coefficient of variation of irregularity $\left(C V_{m} \%\right)$. The imperfection index (IPI) value indicates the total number of the thick place $(+50 \%)$, thin place $(-50 \%)$, and neps $(+200 \%)$ per 1000 meter of yarn [38]. Yarn hairiness $(H)$ corresponds to the total length of protruding fibers (in 
centimeter, $\mathrm{cm}$ ) higher than $4 \mathrm{~mm}$ per $\mathrm{cm}$ length of yarn [38]. EleStretch XT tested yarn strength under the CRE (constant rate of extension) principle following ASTM D1578 standard, which was expressed in terms of CSP (count strength product). Skein strength for each sample yarn was measured and multiplied by yarn linear density to express the CSP in $(\mathrm{kNm} / \mathrm{kg})$ [39]. Yarn elongation was also tested by EleStretch XT according to ASTM D 2256 standard and expressed as the percentage of initial length. The fineness of yarn was tested on USTER $^{\circledR}$ Tester 5, according to ASTM D1907 standard. All the experiments were performed under standard conditions $\left(65 \% \pm 2 \% \mathrm{RH}\right.$ and $\left.20^{\circ} \mathrm{C} \pm 2{ }^{\circ} \mathrm{C}\right)$. Statistical analysis had been carried out by using IBM SPSS Statistics 25 [44]. Regression analysis showed the correlation between spinning system and yarn parameters. The paired-samples t-test procedure was used to check the hypothesis of relationship between two variables.

\section{Results and Discussions}

\subsection{Comparison of Mass Variation}

The mass irregularity indicates the amount of overall mass variation from the mean mass of the sample tested in percentage. Unevenness $(U \%)$ was calculated from the mean deviation, and $C V_{m} \%$ was determined from the standard deviation (SD) of mass per unit length of yarn [38]. The irregularity index (I) was calculated using the Equations (1)-(3). The test results obtained for both compact and rotor yarn are illustrated in Table 4, respectively. Experimental results are used to plot three graphs for $\mathcal{L} \%, C V_{m} \%$, and irregularity index (Figure 5).

Table 4. Parameters of compact and rotor yarn.

\begin{tabular}{|c|c|c|c|c|c|c|c|c|c|c|c|c|c|c|}
\hline \multirow{2}{*}{$\begin{array}{l}\text { Linear } \\
\text { density }\end{array}$} & \multicolumn{2}{|c|}{ Unevenness, $U \%$} & \multicolumn{2}{|c|}{$C V_{m} \%$} & \multicolumn{2}{|c|}{ Irregularity Index $(I)$} & \multicolumn{2}{|c|}{ IPI } & \multicolumn{2}{|c|}{ Hairiness } & \multicolumn{2}{|c|}{ CSP } & \multicolumn{2}{|c|}{ Elongation \% } \\
\hline & $\mathrm{C}$ & $\mathrm{R}$ & $\mathrm{C}$ & $\mathrm{R}$ & $\mathrm{C}$ & $\mathrm{R}$ & $\mathrm{C}$ & $\mathrm{R}$ & $\mathrm{C}$ & $\mathrm{R}$ & $\mathrm{C}$ & $\mathrm{R}$ & $\mathrm{C}$ & $\mathrm{R}$ \\
\hline \multirow{3}{*}{50 Tex } & 7.64 & 8.62 & 9.88 & 10.85 & 1.75 & 1.92 & 11.3 & 5.6 & 5.58 & 7.53 & 3050 & 2321 & 7.01 & 7.78 \\
\hline & 7.83 & 8.91 & 9.84 & 10.7 & 1.74 & 1.89 & 11.8 & 4.9 & 5.54 & 7.5 & 2996 & 2415 & 7.06 & 7.8 \\
\hline & 7.8 & 8.57 & 9.9 & 10.68 & 1.75 & 1.89 & 11.2 & 5.8 & 5.45 & 7.61 & 3160 & 2396 & 6.91 & 8.36 \\
\hline \multirow[t]{2}{*}{$37 \mathrm{Tex}$} & 8.01 & 9.95 & 10.12 & 12.44 & 1.54 & 1.89 & 19.2 & 16 & 5.13 & 5.79 & 3060 & 2380 & 6.5 & 7.63 \\
\hline & 8.09 & 9.95 & 10.43 & 12.31 & 1.59 & 1.87 & 18.6 & 16.1 & 5.15 & 5.89 & 3160 & 2399 & 6.62 & 7.81 \\
\hline \multirow{3}{*}{30 Tex } & 8.34 & 10.88 & 10.44 & 12.98 & 1.43 & 1.78 & 48.6 & 52.4 & 4.86 & 5.11 & 3085 & 2445 & 6.35 & 7.12 \\
\hline & 8.33 & 10.62 & 10.44 & 13 & 1.43 & 1.78 & 52.8 & 54.2 & 4.72 & 4.99 & 3004 & 2432 & 6.4 & 7.24 \\
\hline & 8.48 & 10.49 & 10.42 & 13.12 & 1.43 & 1.8 & 53.2 & 55.1 & 4.68 & 5.08 & 3146 & 2388 & 6.49 & 7.55 \\
\hline \multirow{3}{*}{25 Tex } & 8.9 & 10.7 & 11.55 & 13.55 & 1.44 & 1.69 & 89.4 & 102.6 & 4.21 & 4.56 & 2935 & 2351 & 6.16 & 6.78 \\
\hline & 8.92 & 10.83 & 11.29 & 13.39 & 1.41 & 1.67 & 86.3 & 100.7 & 4.18 & 4.59 & 2899 & 2360 & 6.11 & 6.91 \\
\hline & 8.81 & 10.74 & 11.02 & 13.42 & 1.38 & 1.68 & 88.9 & 99.5 & 4.02 & 4.56 & 3010 & 2391 & 6.02 & 6.75 \\
\hline \multirow{3}{*}{20 Tex } & 9.33 & 11.1 & 11.39 & 13.88 & 1.27 & 1.55 & 167.8 & 208.3 & 3.77 & 4.33 & 3000 & 2443 & 5.95 & 6.56 \\
\hline & 9.11 & 11.96 & 11.8 & 14.02 & 1.32 & 1.57 & 173 & 200.2 & 3.81 & 4.22 & 3102 & 2430 & 5.92 & 6.37 \\
\hline & 9.16 & 12.08 & 11.78 & 13.89 & 1.32 & 1.55 & 165.9 & 194.5 & 3.69 & 4.24 & 3045 & 2379 & 6.02 & 6.4 \\
\hline
\end{tabular}

${ }^{\star} \mathrm{C}=$ Compact yarn, ${ }^{\star} \mathrm{R}=$ Rotor yarn, ${ }^{\star} \mathrm{IPI}=$ Imperfection Index, ${ }^{\star} \mathrm{CSP}=$ Count Strength Product. 


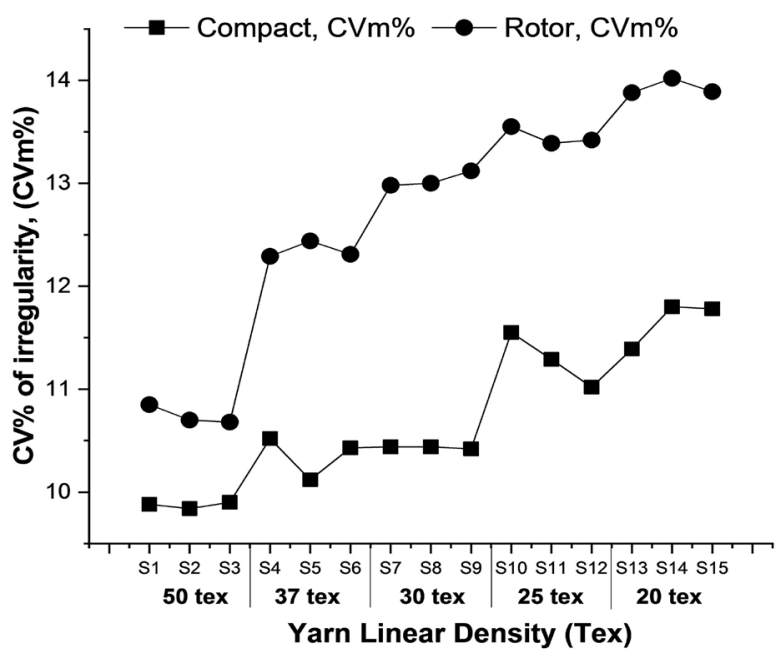

(a)

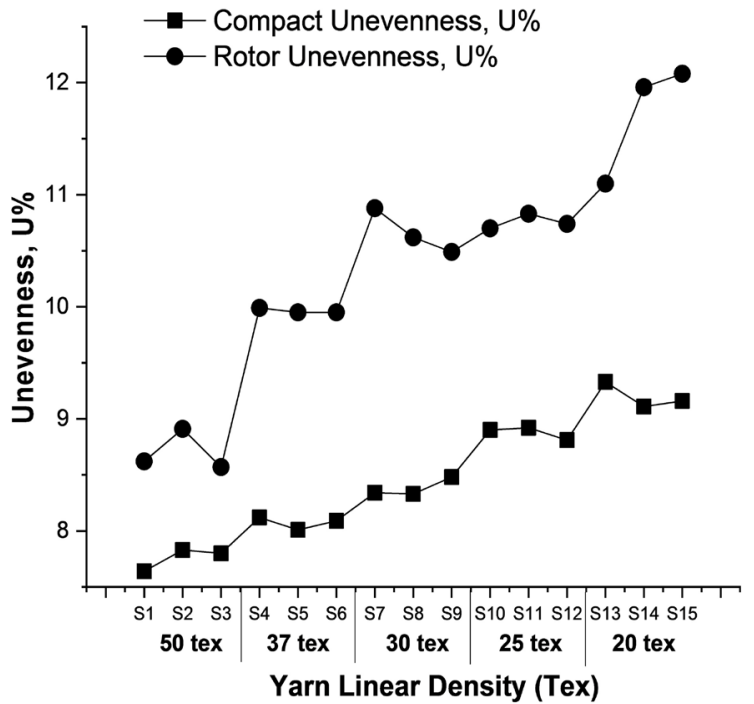

(b)

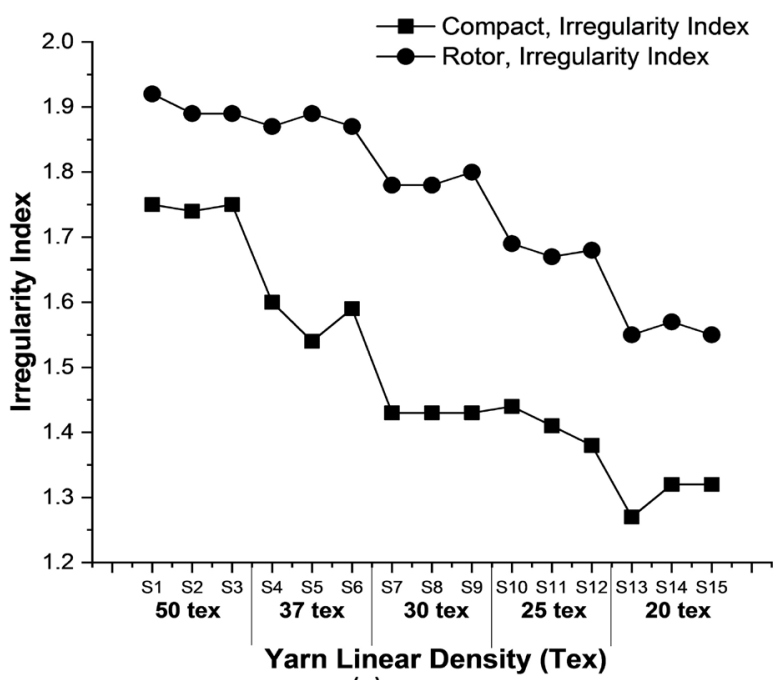

(c)

Figure 5. Comparisons of mass variation. (a) Co-efficient of variation of irregularity $\left(C V_{m} \%\right)$; (b) Unevenness ( $\left.U \%\right)$; (c) Irregularity index (I). 
$U \%$ of the samples spun on the rotor are $10.85 \%$ higher for coarser yarns and $21.5 \%$ higher for finer counts than that of compact yarn. The $C V_{m} \%$ of Suessen compact yarn is also better, which is $8.4 \%$ lower than that of rotor yarns for the coarser count and $19.5 \%$ lower for finer yarns. The irregularity index $(I)$ of compact yarns also lower comparing to rotor samples, which signifies, compact yarn tends to more ideal. From Figure 5, it can be observed that variations in rotor samples are significantly higher. However, there is a slight improvement in unevenness for finer counts (20 Tex) in rotor yarn. This is because, in the case of finer rotor yarns, each fiber gets individualized by the action of combing roller better.

\subsection{Comparison of Imperfection}

Yarn imperfection is related to fiber parameters, as well as the spinning process and environment. The test results of the imperfection index (IPI) obtained for both compact and rotor yarn are illustrated in Table 4, respectively. Experimental results are used to plot a graph for the imperfection index (Figure 6). The amount of thin place in both spinning was found very minimal. However, rotor spun yarn has $23 \%$ more thick places as compared to compact yarn. The compact yarn has a 50.5\% higher IPI as compared to rotor spun yarn for coarser yarns (50 Tex), but as the yarn gets finer, the IPI of the compact is decreased (19\% lower IPI than rotor yarns). Imperfection in finer rotor yarn is usually higher due to low-quality fiber processing. However, the deviations in IPI for both spinning systems are almost equal.

\subsection{Comparison of Hairiness}

Yarn hairiness depends upon the fiber staple length and stiffness, as well as the

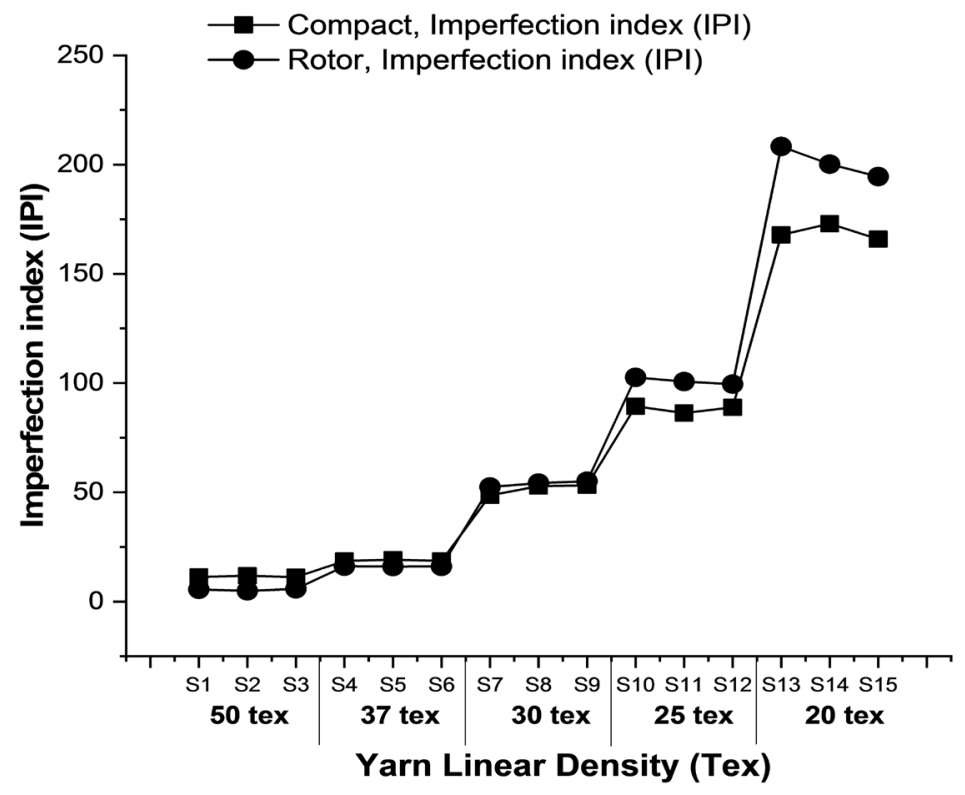

Figure 6. Comparisons of yarn imperfection (imperfection index, IPI). 
spinning process. The test results of yarn hairiness $(H)$ obtained for both compact and rotor yarn are illustrated in Table 4, respectively. Experimental results are used to plot a graph for yarn hairiness ( $H$ ) (Figure 7). It was observed that compact spun yarn had about $25 \%$ less hairiness compared to rotor yarn. In the case of open-end rotor spinning, the fiber strand gets spread and creates hairiness. Analysis indicates the compact spinning tends to produce a better-integrated structure of yarn than open-end rotor spinning. When the yarns become coarser, the amount of fiber in cross-section increases and the suction current may not be strong enough to hold every single fiber effectively. However, the variations in hairiness of compact yarns are slightly higher than rotor ones.

\subsection{Comparison of the Tensile Strength of Yarn}

Tensile strength is a measure of the steady force required to break a specimen and is given experimentally by the maximum load developed in a tensile test [40]. Fiber strength and the spinning process has a massive influence on the yarn strength. The test results of yarn strength (expressed in terms of CSP, $\mathrm{kNm} / \mathrm{kg}$ ) obtained for both compact and rotor yarn are illustrated in Table 4, respectively. Experimental results are used to plot a graph for yarn strength (CSP) (Figure 8). It was observed that the compact spun yarn had $22.5 \%$ higher CSP than that of open-end rotor spun yarn. This shows a clear superiority of the compact spinning. Since the amount of fibers in the cross-section is higher in compact spinning, the compressive load, as well as the tensile strength, becomes significantly higher than rotor yarn. The increasing of tensile strength leads to increased tenacity of compact yarn, meaning the fibers are better condensed in the aerodynamic compacting system. Nevertheless, the variations in CSP of compact yarns are slightly higher than the rotor ones (Figure 8).

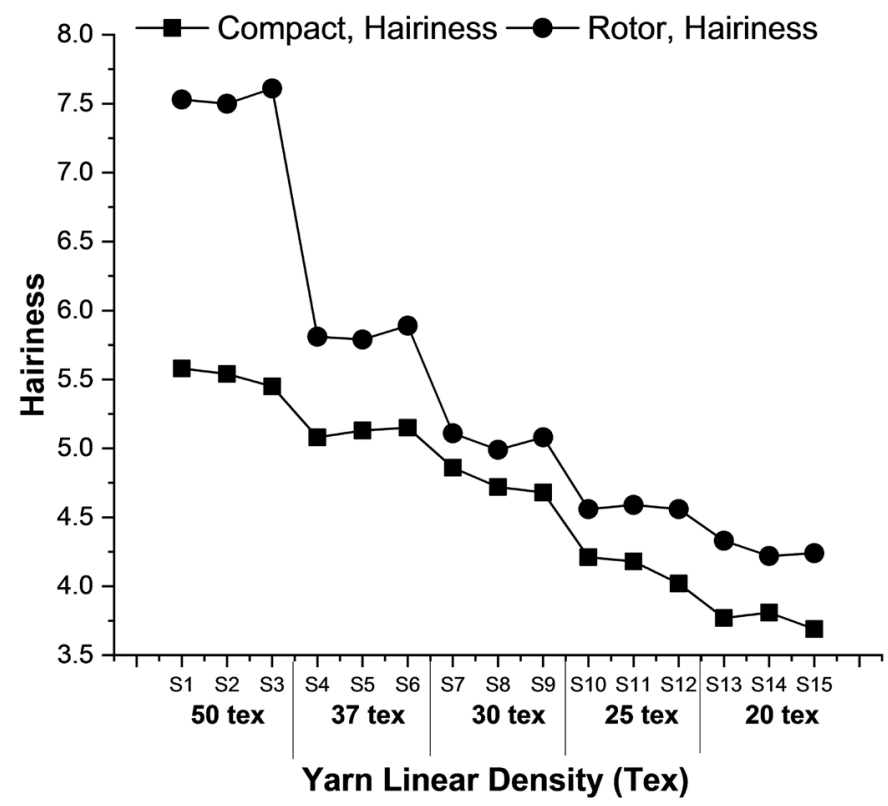

Figure 7. Comparisons of yarn hairiness $(H)$. 


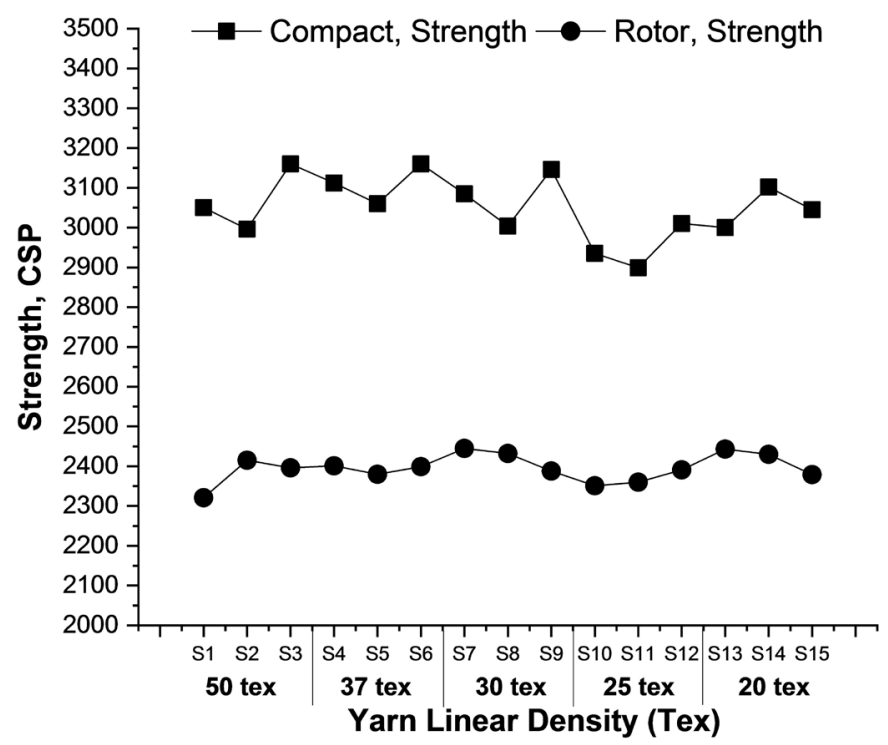

Figure 8. Comparisons of yarn strength (CSP).

\subsection{Comparison of Elongation}

The elongation percentage is the ratio of elongation of the specimen to the initial length thereof expressed as a percentage [40]. The test results of yarn elongation (in percentage) obtained for both compact and rotor yarn are illustrated in $\mathrm{Ta}$ ble 4, respectively. Experimental results are used to plot a graph for yarn elongation\% (Figure 9). It was observed that rotor spun yarn of coarser count had a $12.5 \%$ higher elongation percentage than that of compact yarn. As the yarn gets finer, elongation\% starts to decrease. However, unlike compact yarn, there is less variation in elongation\% of rotor yarn for all samples. When the compact yarn becomes coarser, the effectiveness of condensing the fibers along the condensing zone decreases because the suction current is unable to control and straighten each fiber. Thus, the amount of curled fibers increases as the yarn becomes coarser, thus increasing the elongation $\%$ before yarn breakage.

\subsection{Statistical Analysis}

Paired-samples t-test procedure checks the hypothesis of the relationship between two variables. $H_{0}$ hypothesis (e.g., no relationship between compact yarn count and hairiness) was tested across the alternative hypothesis, and the paired samples correlations and hypothesis tests result for compact yarn linear density (count) values are shown in Table 5 and Table 6. A negative correlation was found between compact yarn count and unevenness\% (-0.951). As the compact yarn count increased, unevenness\% decreased. Similarly, due to negative correlations (-0.906) and (-0.861), as the compact yarn count increased, $C V_{m}$ and IPI value decreased.

On the other hand, due to a positive correlation (0.985) value between compact yarn count and irregularity index $(I)$, as the compact yarn count increased, the $I$ value also increased. Similarly, due to positive correlations (0.956) and (0.979), 


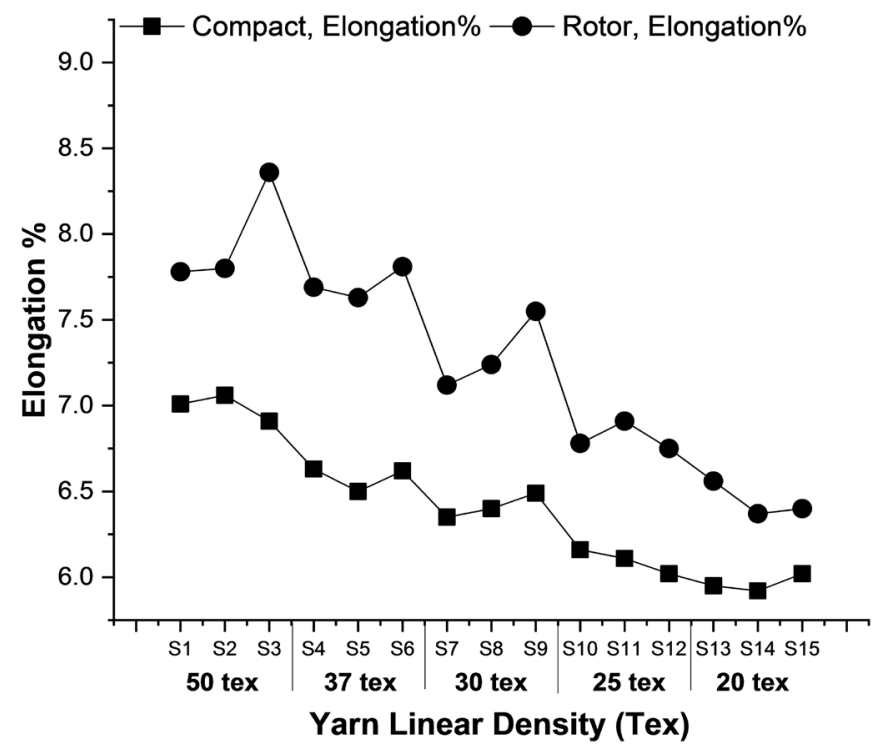

Figure 9. Comparisons of yarn elongation $\%$.

Table 5. Paired samples correlations for compact spinning values.

\begin{tabular}{lcccc}
\hline \multicolumn{5}{c}{ Paired Samples Correlations } \\
\hline Pair 1 & Compact yarn count \& $L \%$ & 15 & Correlation & Sig. \\
Pair 2 & Compact yarn count \& $C V_{m}$ & 15 & -0.951 & 0.000 \\
Pair 3 & Compact yarn count \& I & 15 & 0.906 & 0.000 \\
Pair 4 & Compact yarn count \& IPI & 15 & -0.861 & 0.000 \\
Pair 5 & Compact yarn count \& Hairiness & 15 & 0.956 & 0.000 \\
Pair 6 & Compact yarn count \& CSP & 15 & 0.330 & 0.000 \\
Pair 7 & Compact yarn count \& Elongation & 15 & 0.979 & 0.000 \\
\hline
\end{tabular}

Table 6. Paired samples tests for compact spinning values.

\begin{tabular}{|c|c|c|c|c|c|c|c|c|c|}
\hline \multicolumn{10}{|c|}{ Paired Samples Test } \\
\hline & \multirow{3}{*}{ Pair } & \multicolumn{5}{|c|}{ Paired Differences } & \multirow{3}{*}{$\mathrm{t}$} & \multirow{3}{*}{ df } & \multirow{3}{*}{ Sig. (2-tailed) } \\
\hline & & \multirow{2}{*}{ Mean } & \multirow{2}{*}{ Std. Deviation } & \multirow{2}{*}{$\begin{array}{l}\text { Std. Error } \\
\text { Mean }\end{array}$} & \multicolumn{2}{|c|}{$\begin{array}{l}\text { 95\% Confidence Interval of } \\
\text { the Difference }\end{array}$} & & & \\
\hline & & & & & Lower & Upper & & & \\
\hline 1 & Compact \& $U \%$ & 23.942 & 11.330 & 2.925 & 17.668 & 30.216 & 8.184 & 14 & 0.000 \\
\hline 2 & Compact \& $C V_{m}$ & 21.679 & 11.441 & 2.954 & 15.343 & 28.014 & 7.339 & 14 & 0.000 \\
\hline 3 & Compact \& $I$ & 30.907 & 10.651 & 2.750 & 25.008 & 36.805 & 11.239 & 14 & 0.000 \\
\hline 4 & Compact \& IPI & -35.373 & 68.983 & 17.811 & -73.575 & 2.828 & -1.986 & 14 & 0.067 \\
\hline 5 & Compact \& Hairiness & 27.742 & 10.173 & 2.627 & 22.108 & 33.376 & 10.562 & 14 & 0.000 \\
\hline 6 & Compact \& CSP & -3018.533 & 75.713 & 19.549 & -3060.462 & -2976.605 & -154.409 & 14 & 0.000 \\
\hline 7 & Compact \& Elongation & 25.990 & 10.434 & 2.694 & 20.212 & 31.768 & 9.647 & 14 & 0.000 \\
\hline
\end{tabular}


as the compact yarn count increased, hairiness and elongation value increased. However, a positive correlation value between compact yarn count and strength (CSP) was not significant because the significance value was greater than 0.05 . Table 7 and Table 8 show the paired samples correlations and hypothesis tests result for rotor yarn linear density (count) values. Due to negative correlations $(-0.964),(-0.995)$, and $(-0.861)$, as the rotor yarn count increased, $U \%, C V_{m}$, and IPI value decreased. On the other hand, due to a positive correlation (0.904), (0.993), and (0.919) as the rotor yarn count increased, the irregularity index, hairiness, and elongation value also increased. Nevertheless, a positive correlation value between rotor yarn count and strength (CSP) was not significant because the significance value was greater than 0.05 .

Regression analysis was incurred, and the results are listed in Table 9. It is observed that if compact yarn count is selected as the dependent variable, the coefficient of determination $\left(\mathrm{R}^{2}\right)$ is 0.970 for irregularity index $(I), 0.959$ for elongation, and 0.914 for hairiness. Demonstrated with regression analysis, $I$, elongation, and hairiness was found positively correlated with compact yarn

Table 7. Paired samples correlations for rotor spinning values.

\begin{tabular}{ccccc}
\hline \multicolumn{4}{c}{ Paired Samples Correlations } & \\
\hline Pair 1 & Rotor yarn count \& U\% & N & Correlation & Sig. \\
Pair 2 & Rotor yarn count \& CV & 15 & -0.964 & 0.000 \\
Pair 3 & Rotor yarn count \& I & 15 & -0.995 & 0.000 \\
Pair 4 & Rotor yarn count \& IPI & 15 & 0.904 & 0.000 \\
Pair 5 & Rotor yarn count \& Hairiness & 15 & -0.861 & 0.000 \\
Pair 6 & Rotor yarn count \& CSP & 15 & 0.993 & 0.000 \\
Pair 7 & Rotor yarn count \& Elongation & 15 & -0.259 & 0.352 \\
\hline
\end{tabular}

Table 8. Paired samples tests for rotor spinning values.

\begin{tabular}{|c|c|c|c|c|c|c|c|c|c|}
\hline \multicolumn{10}{|c|}{ Paired Samples Test } \\
\hline & \multirow{3}{*}{ Pair } & \multicolumn{5}{|c|}{ Paired Differences } & \multirow{3}{*}{$\mathrm{t}$} & \multirow{3}{*}{$\mathrm{df}$} & \multirow{3}{*}{ Sig. (2-tailed) } \\
\hline & & \multirow{2}{*}{ Mean } & \multirow{2}{*}{ Std. Deviation } & \multirow{2}{*}{$\begin{array}{l}\text { Std. Error } \\
\text { Mean }\end{array}$} & \multicolumn{2}{|c|}{$\begin{array}{c}95 \% \text { Confidence Interval } \\
\text { of the Difference }\end{array}$} & & & \\
\hline & & & & & Lower & Upper & & & \\
\hline 1 & Rotor \& $U \%$ & 22.041 & 11.833 & 3.055 & 15.488 & 28.593 & 7.214 & 14 & 0.000 \\
\hline 2 & Rotor \& $C V_{m}$ & 19.699 & 11.953 & 3.086 & 13.079 & 26.318 & 6.383 & 14 & 0.000 \\
\hline 3 & Rotor \& $I$ & 30.640 & 10.689 & 2.760 & 24.721 & 36.559 & 11.102 & 14 & 0.000 \\
\hline 4 & Rotor \& IPI & -43.073 & 83.169 & 21.474 & -89.131 & 2.984 & -2.006 & 14 & 0.065 \\
\hline 5 & Rotor \& Hairiness & 26.946 & 9.604 & 2.480 & 21.627 & 32.265 & 10.866 & 14 & 0.000 \\
\hline 6 & Rotor \& CSP & -2363.000 & 39.093 & 10.094 & -2384.649 & -2341.351 & -234.103 & 14 & 0.000 \\
\hline 7 & Rotor \& Elongation & 25.150 & 10.255 & 2.648 & 19.471 & 30.829 & 9.498 & 14 & 0.000 \\
\hline
\end{tabular}


Table 9. Regression analysis for compact yarn and rotor yarn count.

\begin{tabular}{ccccc}
\hline S1 & Variables & $\mathbf{R}^{2}$ (compact yarn count) & $\mathbf{R}^{2}$ (rotor yarn count) \\
\hline 1 & & $U \%$ & 0.904 & 0.928 \\
2 & Mass Variation & $C V_{m}$ & 0.822 & 0.990 \\
3 & & $I$ & 0.970 & 0.817 \\
4 & IPI & 0.742 & 0.741 \\
5 & Hairiness & 0.914 & 0.985 \\
6 & Tensile strength & 0.109 & 0.067 \\
7 & Elongation & 0.959 & 0.845 \\
\hline
\end{tabular}

count. If the dependent variable was selected as rotor yarn count, the coefficient of determination $\left(\mathrm{R}^{2}\right)$ equals to 0.990 for co-efficient variation of irregularity $\left(C V_{m}\right), 0.985$ for hairiness, and 0.928 for $\mathcal{L} \%$. It proved that $C V_{m}$, hairiness, and $\mathrm{U} \%$ are positively correlated with rotor yarn count.

\section{Conclusion}

The above study was carried out to determine the significant differences in the properties of compact and open-end rotor spun yarns, which were influenced by the inner structure of the yarns and their linear density. This was demonstrated in the current work by an analysis of experimental and theoretical assumptions of the geometrical arrangement of fibers in the yarn structures, which indicated a better performance of compact yarns compared to rotor yarn. The study has shown that open-end rotor yarns being composed of core fibers are less parallel compared to aerodynamic compact yarns, which are highly oriented in parallel and also have higher twists. This uniformity makes compact yarn the least hairy between these two. In this regard, the compact spinning effectively controlled the fibers by the condensing process compared to rotor spinning. However, this effectiveness decreased with yarn fineness because the aerodynamic condensing system of the compact spinning technology had better fiber control of finer counts. Again, compact spun yarn shows higher strength, which is a reflection of better fiber migration. Compact yarns are, therefore, stiffer than open-end rotor spun yarns. It can be concluded that compact spun yarn is more effective in terms of irregularity, $C V \%$ of irregularity $\left(C V_{m}\right)$, imperfection, hairiness, strength, and elongation as compared to rotor spinning. Though in the case of coarser yarn, the difference is higher, the difference decreases with the fineness of the yarn. Compact yarn assures better economic benefits for both yarn producers and customers, though its manufacturing cost is higher. On the other hand, the open-end rotor spinning ensures significantly less waste generation.

\section{Acknowledgements}

The authors would like to express thanks and gratitude towards Multazim Spinning Mills Ltd., Valuka, Mymensingh, Bangladesh, for providing machinery and 
equipment on time during this research work and the Zubair Spinning Mills Ltd., Gazipur, Bangladesh, for other assistance that made this work possible. The authors declare that they have no conflict of interest.

\section{Conflicts of Interest}

The authors declare no conflicts of interest regarding the publication of this paper.

\section{References}

[1] Lawrence, C.A. (2003) Fundamentals of Spun Yarn Technology. CRC Press, Boca Raton. https://doi.org/10.1201/9780203009581

[2] Dan Hasanuzzaman, P.K. and Basu, S. (2015) Optimization of Ring-Spinning Process Parameters Using Response Surface Methodology. The Journal of The Textile Institute, 106, 510-522. https://doi.org/10.1080/00405000.2014.929250

[3] Cheng, K.P.S. and Yu, C. (2003) A Study of Compact Spun Yarns. Textile Research Journal, 73, 345-349. https://doi.org/10.1177/004051750307300412

[4] Soe, A.K., Takahashi, M., Nakajima, M., Matsuo, T. and Matsumoto, T. (2004) Structure and Properties of MVS Yarns in Comparison with Ring Yarns and Open-End Rotor Spun Yarns. Textile Research Journal, 74, 819-826. https://doi.org/10.1177/004051750407400911

[5] Basal, G. and Oxenham, W. (2006) Comparison of Properties and Structures of Compact and Conventional Spun Yarns. Textile Research Journal, 76, 567-575. https://doi.org/10.1177/0040517506065591

[6] Rameshkumar, C., Anandkumar, P., Senthilnathan, P., Jeevitha, R. and Anbumani, N. (2008) Comparative Studies on Ring Rotor and Vortex Yarn Knitted Fabrics. Autex Research Journal, 8, 100-105.

[7] Khurshid, M.F., Nadeem, K., Asad, M., Chaudhry, M.A. and Amanullah, M. (2013) Comparative Analysis of Cotton Yarn Properties Spun on Pneumatic Compact Spinning Systems. Fibres \& Textiles in Eastern Europe, 21, 30-34.

[8] Göktepe, F., Yilmaz, D. and Göktepe, Ö. (2006) A Comparison of Compact Yarn Properties Produced on Different Systems. Textile Research Journal, 76, 226-234. https://doi.org/10.1177/0040517506061241

[9] Nikolić, M., Stjepanovič, Z., Lesjak, F. and Štritof, A. (2003) Compact Spinning for Improved Quality of Ring-Spun Yarns. Fibres \& Textiles in Eastern Europe, 11, 30-35.

[10] Kumar, A., Ishtiaque, S. and Salhotra, K. (2003) Compact Spinning: A Critical Review. Paper No: IMECE2003-55321, American Society of Mechanical Engineers, Washington DC. https://doi.org/10.1115/IMECE2003-55321

[11] Altas, S. and Kadoğlu, H. (2012) Comparison of Conventional Ring, Mechanical Compact and Pneumatic Compact Yarn Spinning Systems. Journal of Engineered Fibers and Fabrics, 7, 87-100. https://doi.org/10.1177/155892501200700201

[12] Chellamani, K. (2000) Compact Spinning: Spinning of the Future. Asian Textile Journal, 9, 30-33.

[13] Spinnovation (1999) Sussen Elite Spinning System. Magazine for Spinning Mills, 5, 3-7.

[14] Brunk, N. (2002) Three Years of Practical Experience with the Elite CompactSet in Short-Staple Spinning. Spinnovation, 3, 11. 
[15] Zhibin, L.C.Z. (2009) Application of Suessen Compact Spinning Special Parts. Cotton Textile Technology, 9.

[16] Basal, G. (2003) The Structure and Properties of Vortex and Compact Spun Yarns, in Fiber and Polymer Science. North Carolina State University, Raleigh.

[17] Stahlecker, P. (2003) EliTe CompactSet. Recent Developments and Applications. 62 nd Plenary Meeting of the International Cotton Advisory Committee, Gdańsk, 07-12 September 2003.

[18] Jackowski, T., Cyniak, D. and Czekalski, J. (2004) Compact Cotton Yarn. Fibers \&. Text in Eastern Europe, 12, 22-26.

[19] Lehmann, B. and Herzberg, C. (2016) Yarn Constructions and Yarn Formation Techniques. In: Cherif, C., Ed., Textile Materials for Lightweight Constructions, Springer, Berlin, Heidelberg, 103-157. https://doi.org/10.1007/978-3-662-46341-3 4

[20] Grosberg, P. and Mansour, S. (1975) High-Speed Open-End Rotor-Spinning. The Journal of the Textile Institute, 66, 89-396. https://doi.org/10.1080/00405007508630531

[21] Yilmaz, D., Göktepe, F., Göktepe, Ö. and Kremenakova, D. (2007) Packing Density of Compact Yarns. Textile Research Journal, 77, 661-667. https://doi.org/10.1177/0040517507078796

[22] Ahmad, M.M. (2009) Future Spinning Technology: Compact Spinning. Pakistan Textile Journal, 58, 52-54.

[23] Çelik, P. and Kadoglu, H. (2004) A Research on the Compact Spinning for Long Staple Yarns. Fibres \& Textiles in Eastern Europe, 12, 27-31.

[24] Czekalski, J., Cyniak, D., Jackowski, T. and Sieradzki, K. (2007) Quality of Wool-Type Compact Yarns from Twisted and Rubbed Roving. Fibres \& Textiles in Eastern Europe, 15, 38-44.

[25] Dash, J.R., Ishtiaque, S. and Alagirusamy, R. (2002) Properties and Processibility of Compact Yarns. Indian Journal of Fibre \& Textile Research, 27, 362-368.

[26] Krifa, M. and Ethridge, M.D. (2006) Compact Spinning Effect on Cotton Yarn Quality: Interactions with Fiber Characteristics. Textile Research Journal, 76, 388-399. https://doi.org/10.1177/0040517506062648

[27] Jiang, X., Hu, J.L., Cheng, K.P.S. and Postle, R. (2005) Determining the Cross-Sectional Packing Density of Rotor Spun Yarns. Textile Research Journal, 75, 233-239. https://doi.org/10.1177/004051750507500308

[28] Guo, Y., et al. (2018) Influence of Rotor Speed on Yarn Property and Structure. Cotton Textile Technology, 3, 10.

[29] Ghosh, A. (2006) Studies on Structural Aspects of Ring, Rotor Air Jet and Open-End Friction Spun Yarns. 2006 National Conference on Emerging Trends in Textile, Fibre \& Apparel Engineering, Government College of Engineering \& Textile Technology, Berhampore.

[30] Artzt, P. (1997) The Special Structure of Compact Yarns-Advantages in Downstream Processing, ITB Yarn Fab. Form, 2, 41-48.

[31] Stalder, H. (2000) Ring-Spinning Advance. Textile Asia, 3, 43-46.

[32] Omeroglu, S. and Ulku, S. (2007) An Investigation about Tensile Strength, Pilling and Abrasion Properties of Woven Fabrics Made from Conventional and Compact Ring-Spun Yarns. Fibres \& Textiles in Eastern Europe, 15, 39-42.

[33] Skenderi, Z., Kopitar, D., Ražić, S.E. and Iveković, G. (2019) Study on Physical-Mechanical Parameters of Ring, Rotor and Air-Jet-Spun Modal and Micro 
Modal Yarns. Tekstilec, 62, 42-53. https://doi.org/10.14502/Tekstilec2019.62.42-53

[34] Kumar, A., Salhotra, K. and Ishtiaque, S. (2006) Analysis of Spinning Process Using the Taguchi Method. Part V: Effect of Spinning Processvariables on Physical Properties of Ring, Rotor and Air-Jet Yarns. The Journal of The Textile Institute, 97, 463-473. https://doi.org/10.1533/joti.2005.0111

[35] Arain, F.A., Tanwari, A., Hussain, T. and Malik, Z.A. (2012) Multiple Response Optimization of Rotor Yarn for Strength, Unevenness, Hairiness and Imperfections. Fibers and Polymers, 13, 118-122. https://doi.org/10.1007/s12221-012-0118-8

[36] Ahmed, S., Alimuzzaman, S. and Monjurul Haque, A.K.M. (2020) Effect of Shed Geometry on Starting Mark of Woven Fabric. SN Applied Sciences, 2, Article No. 602. https://doi.org/10.1007/s42452-020-2384-1

[37] Skenderi, Z., Kopitar, D., Vrljičak, Z. and Iveković, G. (2018) Unevenness of Air-Jet Spun Yarn Comparison with Ring and Rotor Spun Yarn Made from Micro Modal Fibers. Tekstilec, 67, 14-26.

[38] USTER ${ }^{\circledast}$ (2009) The Uster $^{\circledR}$ Tester 5. https://www.uster.com/fileadmin/user upload/customer/customer/Knowledge/Tex tile Know How/Yarn testing/U T5 How to avoid hairiness.pdf

[39] Nurwaha, D. and Wang, X.H. (2008) Comparison of the New Methodologies for Predicting the CSP Strength of Rotor Yarn. Fibers and Polymers, 9, 782-784. https://doi.org/10.1007/s12221-008-0122-1

[40] Hearle, J.W. and Morton, W.E. (2008) Physical Properties of Textile Fibres. 4th Edition, Elsevier, Amsterdam, 796.

[41] Su, X.Z., Gao, W.D., Liu, X.J., Xie, C.P. and Xu, B.J. (2015) Research on the Compact-Siro Spun Yarn Structure. Fibres and Textiles in Eastern Europe, 23, 54-57.

[42] Moučková, E., Mertová, I., Jirásková, P., Krupincová, G. and Křemenáková, D. (2015) Properties of Viscose Vortex Yarns Depending on Technological Parameters of Spinning. Autex Research Journal, 15, 138-147. https://doi.org/10.2478/aut-2014-0046

[43] Schwarz, E.R. (1951) Certain Aspects of Yarn Structure. Textile Research Journal, 21, 125-136. https://doi.org/10.1177/004051755102100301

[44] Petrulis, D. and Petrulyte, S. (2017) Packing Properties of Fibres in the OpenPacked Yarn Mode. Fibres \& Textiles in Eastern Europe, 25, 57-61. https://doi.org/10.5604/12303666.1228171 